\title{
Synthesis, solubility, plasma stability, and pharmacological evaluation of novel sulfonylhydrazones designed as anti-diabetic agents
}

This article was published in the following Dove Press journal:

Drug Design, Development and Therapy

9 September 2016

Number of times this article has been viewed

\author{
Gisele Zapata-Sudo',2 \\ Isabelle Karine da Costa \\ Nunes ${ }^{2}$ \\ Josenildo Segundo Chaves \\ Araujo ${ }^{1,2}$ \\ Jaqueline Soares da Silva ${ }^{2}$ \\ Margarete Manhães \\ Trachez ${ }^{2,3}$ \\ Tiago Fernandes da Silva' \\ Filipe $P$ da Costa ${ }^{2}$ \\ Roberto Takashi Sudo 1,2 \\ Eliezer J Barreiro ${ }^{1,2}$ \\ Lídia Moreira Lima ${ }^{1,2}$ \\ 'National Institute of Science and \\ Technology on Drugs and Medicines, \\ Federal University of Rio de Janeiro, \\ Laboratory of Evaluation and \\ Synthesis of Bioactive Compounds, \\ Center of Health Sciences, Rio de \\ Janeiro, Brazil; ${ }^{2}$ Program of Research \\ in Drug Development, Institute \\ of Biomedical Sciences, Federal \\ University of Rio de Janeiro, Rio \\ de Janeiro, Brazil; ${ }^{3}$ Department of \\ Anesthesiology, Fluminense Federal \\ University, Rio de Janeiro, Brazil
}

\begin{abstract}
Neuropathy is a serious complication of diabetes that has a significant socioeconomic impact, since it frequently demands high levels of health care consumption and compromises labor productivity. Recently, LASSBio-1471 (3) was demonstrated to improve oral glucose tolerance, reduce blood glucose levels, and display an anti-neuropathy effect in a murine streptozotocininduced diabetes model. In the present work, we describe the design, synthesis, solubility, plasma stability, and pharmacological evaluation of novel sulfonylhydrazone derivatives (referred to herein as compounds 4-9), which were designed by molecular modification based on the structure of the prototype LASSBio-1471 (3). Among the compounds tested, better plasma stability was observed with 4, 5, and 9 in comparison to compounds 6, 7, and 8. LASSBio-1773 (7), promoted not only hypoglycemic activity but also the reduction of thermal hyperalgesia and mechanical allodynia in a murine model of streptozotocin-induced diabetic neuropathic pain.
\end{abstract}

Keywords: diabetes, sulfonylhydrazone, hypoglycemic activity, druglikeness, plasma stability, metabolite

\section{Introduction}

Neuropathy is a serious complication of diabetes that has a significant socioeconomic impact, since it frequently demands continued health care and compromises labor productivity. ${ }^{1-5}$ Diabetic peripheral neuropathic pain is currently treated based on glycemic control and pain management. ${ }^{6-8}$ Several prototypes and drugs under development are being studied for treatment of diabetic peripheral neuropathic pain. ${ }^{9}$ Recently, Freitag and Miller demonstrated that PPAR agonists could be effective in the treatment of various animal and human pain conditions. ${ }^{10,11}$ Rosiglitazone (1) and pioglitazone (2) are synthetic PPAR $\gamma$ agonists currently used to treat type 2 diabetes mellitus. However, safety concerns including increased plasma creatinine and homocysteine, signs of myopathy and rhabdomyolysis, fluid retention, peripheral edema, weight gain, and a potential increased risk of cardiac failure, bring into question the safety of these drugs. ${ }^{12}$ Zapata-Sudo et al identified new synthetic PPAR $\gamma$ agonists, described as sulfonylhydrazone derivatives; long-term administration $(20 \mathrm{mg} / \mathrm{kg}$, intraperitoneally [ip], for 7 days) of compound 3'-[(E)-[2-[(6-methyl-1,3-benzodioxol-5-yl)sulfonyl] hydrazinylidene]methyl]benzoic acid (3, LASSBio-1471) improved oral glucose tolerance, reduced blood glucose levels, and reduced neuropathic pain in a murine streptozotocin (STZ)-induced diabetes model. ${ }^{13}$

This work describes the design, synthesis, solubility, plasma stability, and pharmacological evaluation of novel sulfonylhydrazones (referred to herein as compounds 4-9),
Correspondence: Lídia Moreira Lima Federal University of Rio de Janeiro, CCS, Bloco B, Sala I4, PO Box 68024, Rio de Janeiro, RJ, 2194I-97I, Brazil Tel/fax +552139386503 Email lidia@lassbio.icb.ufrj.br (c) (1) \& $\odot 2016$ Lapata-Sudo et al. This work is published and licensed by Dove Medical Press Limited. The full terms of this license are available at https://www.dovepress.com/terms.php cc. hereby accept the Terms. Non-commercial uses of the work are permitted without any further permision from Dove Medical Press Limited, provided the work is properly atributed. For permission for commercial use of this work, please see paragraphs 4.2 and 5 of our Terms (htpps://www.dovepress.com/terms.php). 


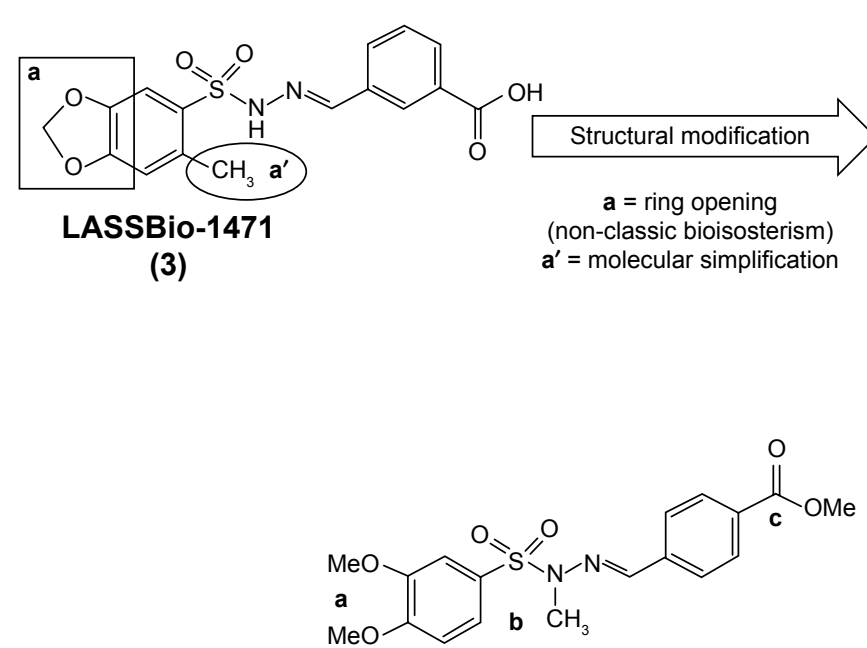

LASSBio-1774

(6)

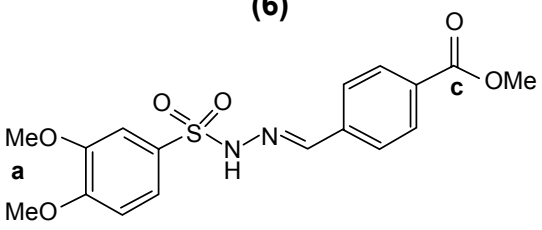

LASSBio-1773

(7)

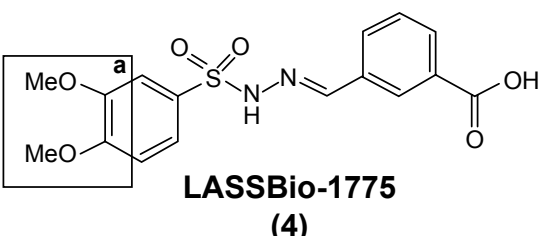

(4)
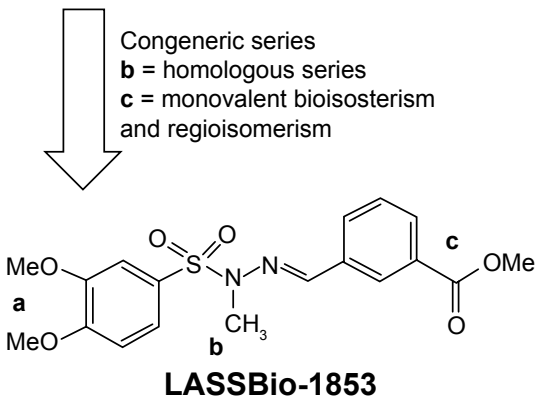

(5)

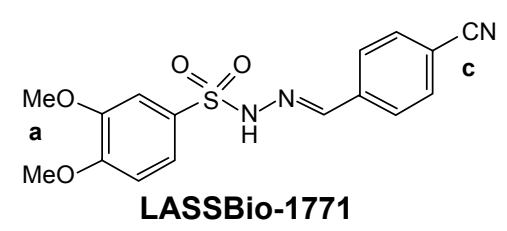

(8)

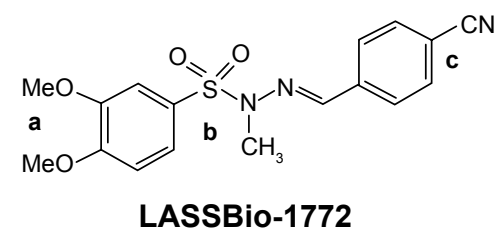

(9)

Figure I Genesis concept of the novel sulfonylhydrazones 4-9 from molecular modifications based on prototype 3.

designed by molecular modification based on the structure of prototype LASSBio-1471 (3) (Figure 1).

\section{Results and discussion}

Compounds 4-9 were synthetized as depicted in Figure 2. Sulfonylhydrazones 4,7 , and 8 were prepared in two linear steps based on hydrazinolysis of starting material 11 followed by condensation with functionalized aldehydes to produce good yields of the target compounds. ${ }^{14} \mathrm{~N}$-methylsulfonylhydrazone analogs $(5,6$, and 9$)$ were synthetized in a similar manner using $\mathrm{N}$-methyl-sulfonylhydrazide 13 as a key intermediate. This compound was obtained with 39.5\% overall yield through protection from phthalic anhydride, followed by N-methylation with methyl iodide and deprotection of phthalimide, using hydrazine hydrate in ethanol (Figure 2). ${ }^{15,16}$ The ${ }^{1} \mathrm{H}$ and ${ }^{13} \mathrm{C}$ nuclear magnetic resonance (NMR) spectral analysis of compounds 4-9 revealed the presence of only one signal related to imine hydrogen $(\mathrm{N}=\mathrm{CH})$, indicating that compounds were synthesized as a single isomer. The assignment of the possible geometrical isomer obtained (ie, $Z$ or $E$ ) was performed considering the chemical shift of the imine hydrogen and based on previous data from literature. ${ }^{13-17}$ These data indicated that compounds 4-9 were obtained as $E$-diastereoisomers $(\mathrm{N}=\mathrm{CH}$ in configuration E).

In order to obtain information about the druglikeness profile of compounds 4-9, their cLogP, and tPSA were calculated in silico and their aqueous solubility and $\mathrm{pKa}$ values were determined using ultraviolet spectrometry. ${ }^{18,19}$ The data summarized in Table 1 showed that compounds 4-9 have ideal cLogP values and satisfactory to good aqueous solubility, with the exception of compound 6 (LASSBio-1774).

The chemical stability of sulfonylhydrazones 4-9 in buffer solution with $\mathrm{pH}$ values that simulate gastric acid $(\mathrm{pH}=2.0)$ and serum content ( $\mathrm{pH} 7.4)$ was investigated. ${ }^{20}$ As shown in Figure 3A and B, all compounds presented great chemical stability, with the exception of compound 8 that was unstable at $\mathrm{pH} 2.0$.

Compounds 4-9 were also studied in order to determine their plasma stability. ${ }^{20,21}$ After 60 minutes incubation with 
<smiles>COc1ccc(S(=O)(=O)Cl)cc1OC</smiles>

(11)<smiles>COc1ccc(S(=O)(=O)NN)cc1OC</smiles>

(12)<smiles>COc1ccc(S(=O)(=O)N/N=C/c2cccc(C(C)C)c2)cc1OC</smiles>

$\mathrm{W}=3-\mathrm{CO}_{2} \mathrm{H}(4)$

$\mathrm{W}=4-\mathrm{CO}_{2} \mathrm{Me}(7)$;

$\mathrm{W}=4-\mathrm{CN}(8)$

$\mathrm{W}=4-\mathrm{CO}_{2} \mathrm{H}(10)$<smiles>COc1ccc(S(=O)(=O)N(C)N)cc1OC</smiles>

(13)

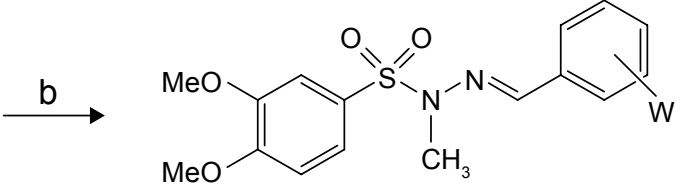

$\mathrm{W}=3-\mathrm{CO}_{2} \mathrm{Me} \mathrm{(5)} ;$
$\mathrm{W}=4-\mathrm{CO}_{2} \mathrm{Me} \mathrm{(6)} ;$
$\mathrm{W}=4-\mathrm{CN}(9)$

Figure 2 Reagents and conditions.

Notes: a) $\mathrm{NH}_{2} \mathrm{NH}_{2} \cdot \mathrm{H}_{2} \mathrm{O}, \mathrm{CHCl}_{3}, \mathrm{rt}, 4$ hours, $91 \%$; b) ArCHO, rt, 0.5 hour, $62 \%-99 \%$; c) i) phthalic anhydride, $130^{\circ} \mathrm{C}, 2$ hours, $93 \%$; ii) $1 \mathrm{CH}$, acetone, $50^{\circ} \mathrm{C}$, 18 hours, $72 \%$; iii) $\mathrm{NH}_{2} \mathrm{NH}_{2} \cdot \mathrm{H}_{2} \mathrm{O}, \mathrm{EtOH}, 80^{\circ} \mathrm{C}, 59 \%$.

rat plasma, compounds 4,5 , and 9 were very stable, while compounds 6, 7, and 8 were unstable (Table 2). Only $2.2 \%$ and $9.6 \%$ of compounds 6 and 7 , respectively, were recovered after plasma incubation, indicating the high lability of the ester subunit. A mass chromatogram was obtained from the analysis of compounds 7 and 8 and their metabolites, generated using rat plasma, by high performance liquid chromatography/mass spectrometry (HPLC/MS) (Figures 4 and 5). As shown in Figure 4B, the metabolite $M$ of compound 7 (LASSBio-1773) appears at retention time 4.57 and displays a peak with $\mathrm{m} / \mathrm{z}$ value of 363.04 in negative mode suggestive of metabolite resulting from the loss of 15 atomic units, indicating the possibility of the hydrolysis of carboxymethyl ester moiety, presented in the structure of compound 7 ( $\mathrm{m} / \mathrm{z}$ 378.04). In order to unequivocally identify the plasma metabolite of compound 7 , carboxylic acid derivative 10 was

Table I Physicochemical properties and aqueous solubility of compounds 4-9

\begin{tabular}{llllll}
\hline Compound & cLogPa $^{\mathbf{a}}$ & tPSA $^{\mathbf{a}}$ & $\mathbf{p K a}^{\mathrm{b}}$ & \multicolumn{2}{l}{$\begin{array}{l}\text { Aqueous } \\
\text { solubility }\end{array}$} \\
\cline { 3 - 6 } & & & & $\mathbf{m g} / \mathbf{m L}$ & $\mu \mathrm{M}$ \\
\hline 4 & 2.5 & 114.29 & 6.69 & 0.011063 & 30.38 \\
5 & 3.7 & 94.50 & $\mathrm{ND}^{\mathrm{d}}$ & 0.013580 & 34.60 \\
6 & 3.7 & 94.50 & $\mathrm{ND}^{\mathrm{d}}$ & 0.000242 & 0.60 \\
7 & 2.9 & 103.29 & 6.86 & 0.001282 & 3.00 \\
8 & 2.6 & 100.78 & 6.35 & 0.021275 & 62.00 \\
9 & 3.4 & 91.99 & $\mathrm{ND}^{d}$ & 0.001983 & 5.00 \\
\hline
\end{tabular}

Notes: ${ }^{a} \mathrm{CLogP}$ and tPSA were calculated using ChemDraw Ultra 10.0 Program (license number: 530-041282-2117); b the pKa values of $\mathrm{NH}$-compounds were determined using ultraviolet spectroscopy, as described by Martínez and Dardonville; 19 csolubility was determined using ultraviolet spectroscopy, as described by Schneider et al. ${ }^{19}$ d Not determined. synthetized (Figure 2) and co-injected for 60 minutes incubation with rat plasma samples. The ultraviolet spectroscopy (UV) analysis of synthesized metabolite 10 presented a great correlation with the rat plasma metabolite M (Figure 4D-F), and a complete superposition between the peaks of metabolite $M$ and the standard 10 was observed (Figure 4G). Considering that the cyano group, presented in compound 8 , can also be hydrolyzed to the corresponding carboxylic acid, the same methodology was applied for the analysis of its metabolite (Figure 5A-F). As shown in Figure 5B and C, the plasma metabolite of compound 8 (m/z 345.09) appears at the same retention time (4.57) as the metabolite identified for compound 7 , and displayed a peak with an $\mathrm{m} / \mathrm{z}$ value of 363.09. These results were suggestive of hydrolysis of the cyano subunit. To confirm this hypothesis, carboxylic acid derivative 10 was co-injected for 60 minutes incubation with rat plasma samples previously treated with compound 8 . The UV analysis of the standard 10 and the plasma metabolite of compound 8 presented higher correlation and great overlap between the peaks of metabolite $\mathrm{M}$ and the standard 10 (Figure 5E and F).

The anti-diabetic profile of compounds 4-9 was investigated through the evaluation of their ability to reduce blood glucose levels in a murine model of diabetes induced by STZ. ${ }^{13,14}$ Among these compounds, only sulfonylhydrazones 6 and 7 showed hypoglycemic activity. After ip administration of a single dose, LASSBio-1773 (20 mg. $\left.\mathrm{kg}^{-1}\right)$ (7) significantly reduced blood glucose from $384.0 \pm 41.9 \mathrm{mg} / \mathrm{dL}$ to $182.2 \pm 22.7 \mathrm{mg} / \mathrm{dL}$ and LASSBio-1774 (6) reduced it from $397.1 \pm 38.2 \mathrm{mg} / \mathrm{dL}$ to $255.3 \pm 42.2 \mathrm{mg} / \mathrm{dL}$ (Figure 6). 

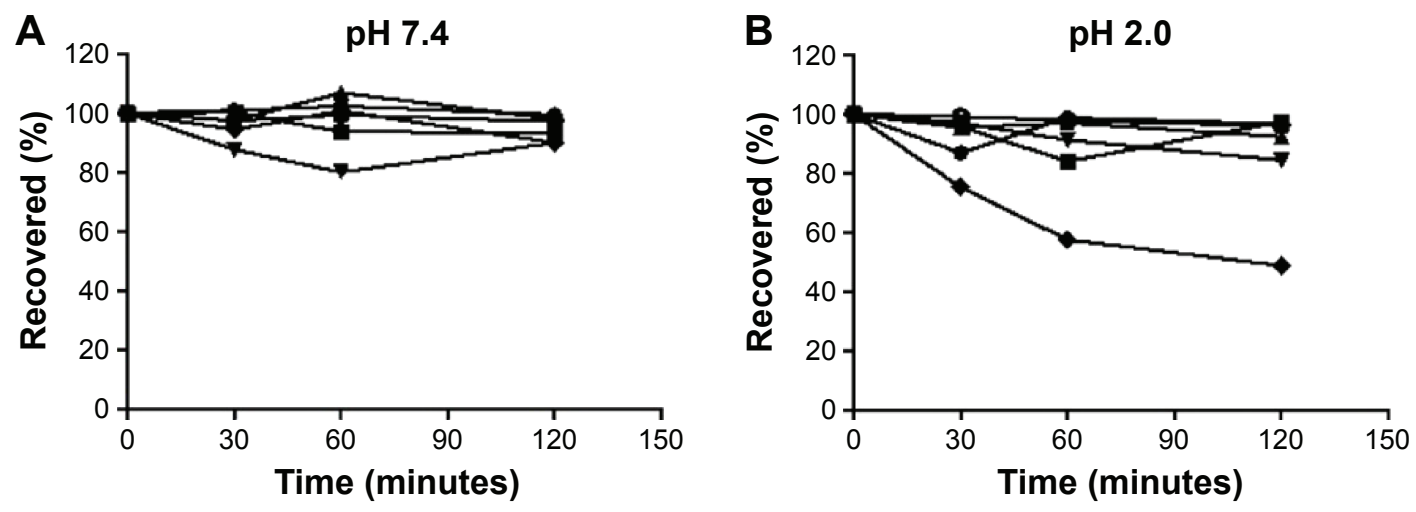

$\bullet 4-5 \pm 6 \rightarrow 7 \multimap 8 \bullet 9$

Figure 3 In vitro chemical stability.

Notes: Compounds 4-9 (20 $\mu \mathrm{M})$ were evaluated for their chemical stability at $\mathrm{pH} 7.4(\mathbf{A})$ and at $\mathrm{pH} 2.0$ (B). The percentage of compound remaining was calculated through ratio of peak area at each time point to peak area found at 0 minute multiplied by 100 . The values are the mean of at least two experiments in triplicate.

Compound 9 (LASSBio-1772) did not reduce hyperglycemia after treatment with a single dose (Figure 6), although it was recently described by Lima et al as a partial agonist of PPAR $\gamma .{ }^{14}$ When administered for 7 days at a dose of $50 \mathrm{mg} / \mathrm{kg}$, it produced a significant reduction in glucose levels $(242.4 \pm 55.3$ $\mathrm{mg} / \mathrm{dL})$ when compared to vehicle $(410.0 \pm 58.0 \mathrm{mg} / \mathrm{dL})$.

Additionally, we investigated the anti-diabetic profile of sulfonylhydrazone 7 (LASSBio-1773) during administration of $50 \mathrm{mg} / \mathrm{kg}$ once a day for 7 days. The effect on blood glucose levels was measured before and 3 and 7 days after treatment with LASSBio-1773 (7). As shown in Table 3, compound 7 promoted hypoglycemic activity only after 7 days of treatment.

Considering the fact that the sulfonylhydrazone 9 (LASSBio-1772), which has high chemical and plasma stability (Tables 1 and 2), had been described as an antinociceptive agent in a diabetic neuropathic pain model induced by STZ in rats, ${ }^{14}$ analog 7 (LASSBio-1773) was selected to be

Table 2 In vitro stability of compounds 4-9 in rat plasma

\begin{tabular}{lll}
\hline $\begin{array}{l}\text { Compound } \\
(20 \mu \mathrm{M})\end{array}$ & $\begin{array}{l}\text { Rat plasma } \\
\text { \% recovered amount } \\
\text { after } \mathbf{6 0} \text { minutes }^{\mathbf{a}}\end{array}$ & $\mathbf{t}_{\mathrm{1} / 2}(\mathbf{m i n})^{\mathrm{b}}$ \\
\hline 4 & $>90$ & $\mathrm{ND}^{\mathrm{c}}$ \\
5 & $>90$ & $\mathrm{ND}^{\mathrm{c}}$ \\
6 & 2.2 & $\mathrm{ND}^{\mathrm{c}}$ \\
7 & 9.6 & 15 \\
8 & 35.1 & 25.6 \\
9 & 86.5 & 264 \\
\hline
\end{tabular}

Notes: ${ }^{\text {TT }}$ The percentage of compound remaining was calculated through ratio of peak area at 60 minutes to peak area found at 0 minutes multiplied by 100 . The values are the mean of at least three experiments in duplicate. ${ }^{b}$ Plasma half-life $\left(\mathrm{t}_{1 / 2}\right)$ was calculated using the expression $\mathrm{t}_{1 / 2}=0.693 / a$, and $a$ is a straight slope of the natural log of sample concentration vs incubation time. 'Not determined. evaluated on the same experimental model. As shown in Figure 7, long-term administration of compound 7 (dose $50 \mathrm{mg} \cdot \mathrm{kg}^{-1}$, ip) reduced diabetic neuropathic pain. Four weeks after induction of diabetes, the paw withdrawal latency (PWL, Figure 7A) and paw withdrawal threshold (PWT, Figure 7B) were significantly reduced from $13.0 \pm 0.4 \mathrm{~s}$ to $8.5 \pm 0.2 \mathrm{~s}$ and from $39.8 \pm 0.2 \mathrm{~g}$ to $24.0 \pm 1.4 \mathrm{~g}$, respectively, showing the induced diabetic neuropathy. Compound 7 (LASSBio-1773) significantly increased the PWL from $8.5 \pm 0.2$ seconds to $12.2 \pm 0.9$ seconds and $13.3 \pm 0.2$ seconds, after 3 and 7 days of treatment, respectively (Figure 7A). It also increased the PWT from $24.0 \pm 1.4 \mathrm{~g}$ to $36.7 \pm 0.9 \mathrm{~g}$ (Figure $7 \mathrm{~B}$ ).

In order to investigate the mechanism of the action of compounds 4-9 and considering that these compounds were designed based on molecular modification of the prototype LASSBio-1471 (3), previously described as PPAR $\gamma$ ligand, ${ }^{14}$ PPAR $\gamma$ binding assay was performed by CEREP ${ }^{\circledR}$, employing a single concentration of compounds 4-9 (C=30 $\mu \mathrm{M})$ using rosiglitazone as positive control. In this model, these compounds were not able to inhibit the control specific binding to PPAR $\gamma$. In a similar manner, compound 10 , identified as the plasma metabolite of 7 and 8 , was also evaluated and was unable to bind to PPAR (data not shown).

In summary, a new series of sulfonylhydrazones (4-9) was synthetized, and their druglikeness profile (including cLogP, aqueous solubility, and $\mathrm{pKa}$ ), and chemical and plasma stability were determined. From this series, compounds 4, 5, and 9 showed the best plasma stability, while compounds 6,7 , and 8 presented high instability in rat plasma. Considering their pharmacological profile, LASSBio-1773 (7) has displayed expressive hypoglycemic activity, by intraperitoneal administration, in a diabetes 
A



C

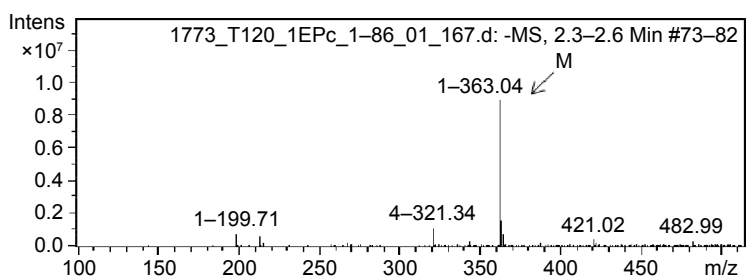

E

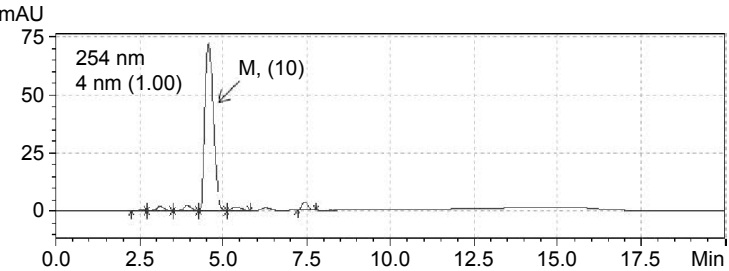

G

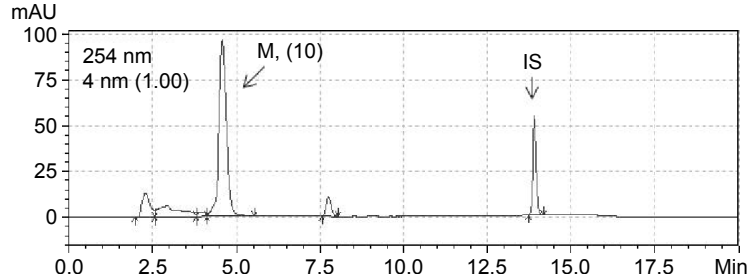

B

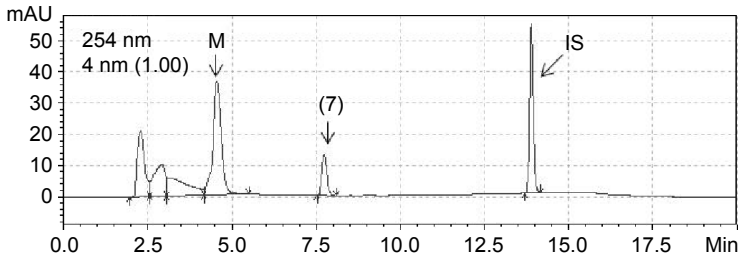

D

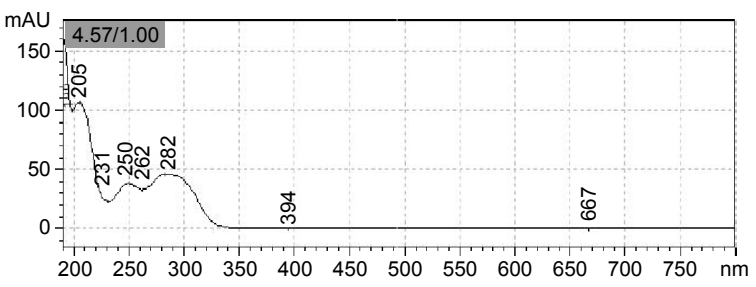

$\mathbf{F}$

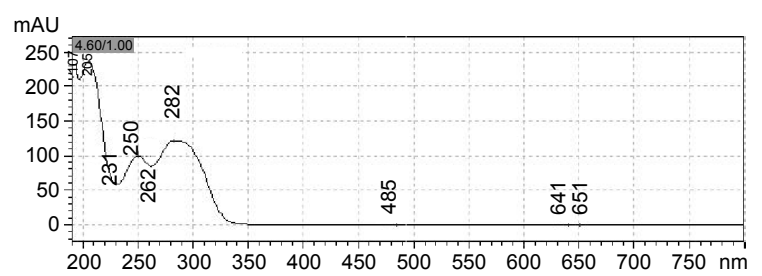

H

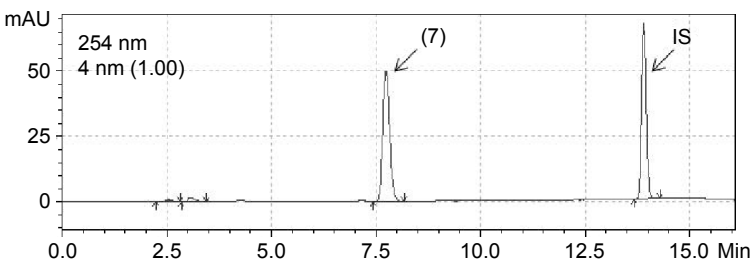

Figure 4 Representative chromatograms of LASSBio- $1773(7)(20 \mu \mathrm{M})$ and its metabolite formed by incubation with rat plasma.

Notes: (A) Incubation in rat plasma at 0 minute; (B) incubation in rat plasma at I hour, and appearance of metabolite (M) formed at 4.57 minutes; (C) HPLC/MS ion scan of $\mathrm{M}[\mathrm{M}-\mathrm{H}]^{-}$at $\mathrm{m} / \mathrm{z} 363.09$ (retention time at 4.57); (D) UV chromatogram of $M$ at 4.57 minutes; (E) synthesized M standard (I0); (F) UV chromatogram of standard (I0) at 4.57 minutes; (G) co-injection of M standard (I0) in I hour rat plasma experiment; (H) compound and internal standard (IS) in acetonitrile. IS: internal standard (eg, biphenyl-

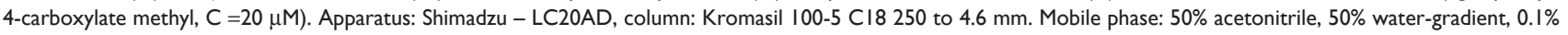
formic acid, flow: I mL/min. Detector: SPD-M20A (Diode Array); wavelength: $254 \mathrm{~nm}$. The mass spectrometer analyses were performed by the mass spectrometer model Esquire 6000 - ESI lon Trap MSn System Bruker Daltonics (LASSBio ${ }^{-}$-UFRJ). 'M' refers to the metabolite of the compound.

Abbreviations: HPLC/MS, high performance liquid chromatography/mass spectrometry; min, minutes; Intens, Intensity.

model induced by STZ. It was also able to reduce the thermal hyperalgesia and mechanical allodynia in a murine model of diabetic neuropathic pain induced by STZ. These activities seem not to be related to the PPAR $\gamma$, since these compounds were not able to bind to these receptors. The mechanism of action of these compounds is now under investigation.

\section{Experimental pharmacology}

All experiments were approved by the Ethics Committee on Animal Use in Scientific Experimentation Center of Health Sciences, Federal University of Rio de Janeiro which follows the guidelines and is registered with the National Board of Animal Experimentation Control. Animals were housed three per cage at constant temperature of $23^{\circ} \mathrm{C} \pm 2{ }^{\circ} \mathrm{C}$ under 12-hour light/dark cycle, with food and water ad libitum.

The compounds were tested in diabetic rats (Rattus norvegicus). Experimental diabetes was induced through a single intravenous injection of STZ $\left(60 \mathrm{mg} \cdot \mathrm{kg}^{-1}\right.$; SigmaAldrich Co., St Louis, MO, USA) dissolved in citrate buffer (pH 4.5). After 4 weeks, male Wistar rats (R. norvegicus weighing 180-220 g) with glycemia $>300 \mathrm{mg} / \mathrm{dL}$ were considered diabetic. Animals were randomly divided into three groups: non-diabetic, diabetic treated with solvent polyethylene glycol (dimethyl sulfoxide [DMSO], Merck Millipore, Billerica, MA, USA), and diabetic treated with compounds. Compounds 4-9 were administered at a single 

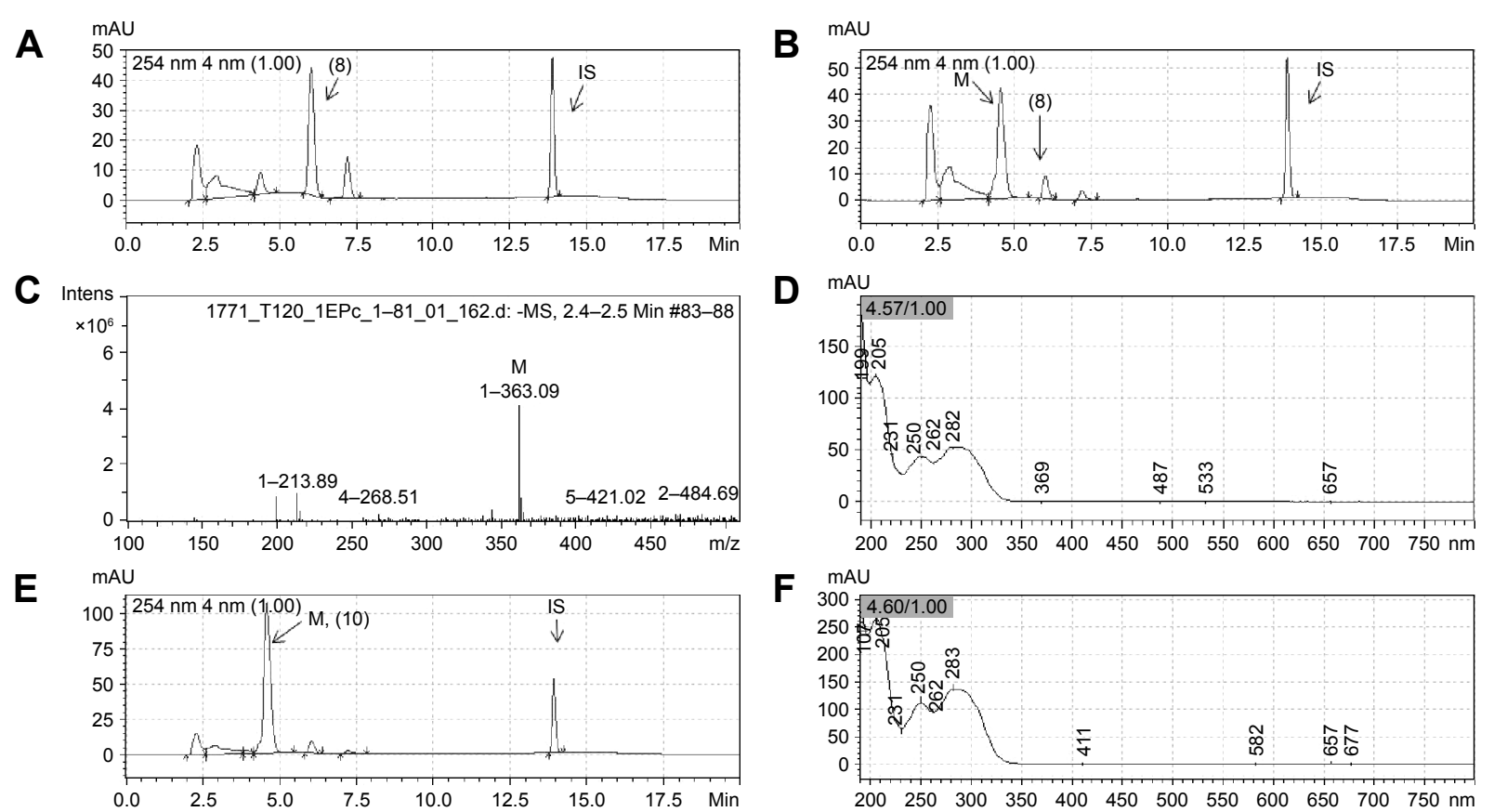

Figure 5 Representative chromatograms of LASSBio-I77I (8) $(20 \mu \mathrm{M})$ and its metabolite formed by incubation with rat plasma.

Notes: (A) Incubation in rat plasma at 0 minute; (B) incubation in rat plasma at I hour, and appearance of metabolite (M) formed at 4.57 minutes; (C) HPLC/MS ion scan of $M$ [M-H] $]^{-}$at m/z 363.09 (retention time at 4.57); (D) UV chromatogram of M at 4.57 minutes; (E) co-injection of synthesized standard M (I0) in I hour rat plasma experiment (M); (F) UV chromatogram of standard (I0) at 4.57 minutes. IS: internal standard (eg, methyl biphenyl-4-carboxylate, C =20 $\mu$ M). Apparatus: Shimadzu - LC20AD, column: Kromasil 100-5 CI8 250 to $4.6 \mathrm{~mm}$. Mobile phase: 50\% acetonitrile, 50\% water-gradient, 0.1\% formic acid, flow: I mL/min. Detector: SPD-M20A (Diode Array); wavelength: 254 nm. The mass spectrometer analyses were performed by the mass spectrometer model Esquire 6000 - ESI lon Trap MSn System Bruker Daltonics (LASSBio ${ }^{\circledR}$-UFRJ).

Abbreviations: HPLC/MS, high performance liquid chromatography/mass spectrometry; min, minutes; UV, ultraviolet spectroscopy; Intens, Intensity.



Figure 6 Activity of compounds 4-9 in a murine model of diabetes induced by streptozotocin.

Notes: Compounds were evaluated after a single dose $\left(20 \mathrm{mg} \cdot \mathrm{kg}^{-1}\right.$, intraperitoneally). Values are mean \pm standard error of the mean; $n=7$ per group. Student's $t$-test with $P<0.05$ was considered significant. $* P<0.05$ compared to the time control. Compound 5 was partially insoluble in DMSO.

Abbreviation: DMSO, dimethyl sulfoxide. dose $\left(20 \mathrm{mg} \cdot \mathrm{kg}^{-1}\right.$, ip) and plasma glucose levels were measured at $0,30,60,120$, and 180 minutes after treatment, using commercial kit Accu-Chek ${ }^{\circledR}$ Performa Monitoring System (Hoffman-La Roche Ltd., Basel, Switzerland). The anti-diabetic profile was also observed during long-term administration of compound 7 at a dose of $50 \mathrm{mg} / \mathrm{kg}$, ip.

\section{Nociceptive test}

\section{Thermal hyperalgesia and mechanical allodynia}

Thermal hyperalgesia was determined by measuring PWL assessed by applying radiant heat to the hind paw using a plantar analgesia meter (model 33ITC Inc., CA, USA). Mechanical allodynia was determined by measuring PWT to pressure applied to the hind paw using a digital analgesiometer (model EFF301, Insight, São Paulo, Brazil). PWL, PWT, and plasma glucose were determined before and after 4 weeks of diabetes induction, as well as 3 and 7 days after treatment with compound 7 (LASSBio-1773) at a dose of $50 \mathrm{mg} \cdot \mathrm{kg}^{-1} \mathrm{ip}$.

\section{Statistical analysis}

Values are expressed as mean \pm standard error of the mean and analyzed using GraphPrism software (version 5.0). One-way analysis of variance (ANOVA) test followed by Dunnett post-tests or ANOVA two-way test were used for 
Table 3 Evaluation of blood glucose levels $(\mathrm{mg} / \mathrm{dL})$ in diabetic rats treated with vehicle (DMSO) and LASSBio- 1773 (7), $50 \mathrm{mg} \cdot \mathrm{kg}^{-1}$, ip for 7 days

\begin{tabular}{llll}
\hline Blood glucose levels $(\mathbf{m g} / \mathbf{d L})$ & & & \\
\hline Group & Before treatment & 3 days' treatment & 7 days' treatment \\
\hline Non diabetic $(n=5)$ & $100.4 \pm 4.93^{* * *}$ & $90.8 \pm 3.4^{* * *}$ & $107.2 \pm 6.53^{* * *}$ \\
STZ + vehicle $(n=6)$ & $461.9 \pm 27.33$ & $494.0 \pm 33.3$ & $508.1 \pm 14.3$ \\
STZ + LASSBio- $1773(n=8)$ & $511.1 \pm 26.7$ & $395.6 \pm 40.76$ & $363.5 \pm 52.26^{\#}$ \\
\hline
\end{tabular}

Notes: Effect of administration of LASSBio-1773 (7) (50 mg/kg/day, 7 days, ip) on glucose levels at three times: before treatment, 3 , and 7 days after treatment. Values are expressed as mean \pm standard error of the mean. One-way analysis of variance (ANOVA) test followed by Dunnett post-tests or a two-way ANOVA test followed by Bonferroni were used for comparisons among groups. ${ }^{* * * P}<0.001$ compared to normal group and ${ }^{\#} P<0.01$ compared to vehicle (DMSO).

Abbreviations: DMSO, dimethyl sulfoxide; STZ, streptozotocin; ip, intraperitoneally.

comparisons among groups, and were considered significant for all tests with a minimum of $P<0.05$.

\section{Chemical - HPLC/UV}

In this study, we reported the synthesis of new sulfonylhydrazone derivatives (4-9). Structural characterizations of the synthesized compounds were made by using spectroscopic methods, magnetic measurements, and thermal studies. Melting points were determined using Quimis 340 apparatus and are uncorrected. ${ }^{1} \mathrm{H}$ NMR spectra were determined in deuterated chloroform or DMSO containing approximately $1 \%$ tetramethylsilane as an internal standard, using Bruker DPX-200 at $200 \mathrm{MHz} .{ }^{13} \mathrm{C}$ NMR spectra were determined with the same spectrometer at $50 \mathrm{MHz}$, using the same solvents. The progress of all reactions was monitored through

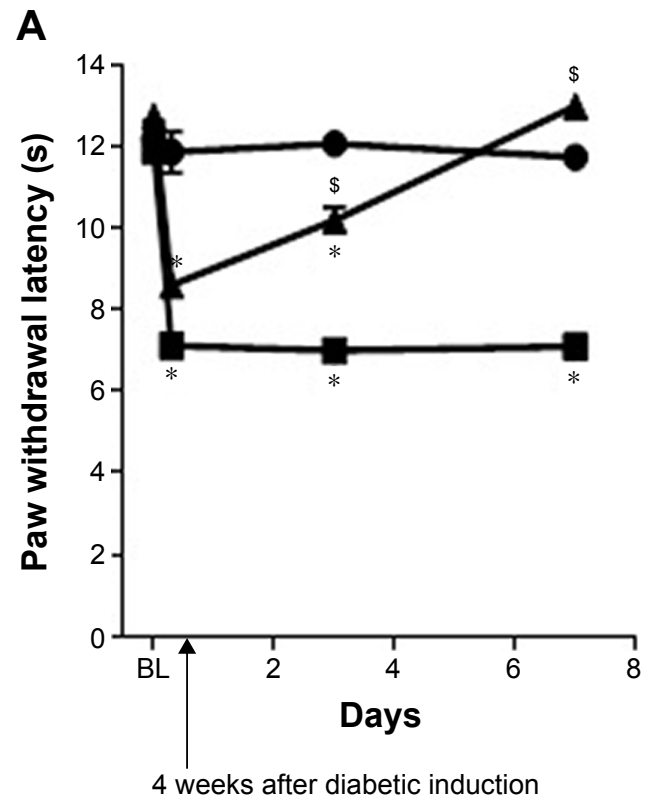

thin layer chromatography (HF-254, Merck Millipore). The developed chromatograms were viewed under ultraviolet light (254-265 nm) and treated with iodine vapor. Reagents and solvents were purchased from commercial suppliers and used as received.

Purity of compounds 4-9 and metabolite 10 was determined through HPLC (>95\%) using Shimadzu - LC20AD apparatus, Kromasil 100-5C18 (4.6 mm/6,250 mm) column, and SPD-M20A detector (Diode Array) at $254 \mathrm{~nm}$ for quantification of analyte in a $1 \mathrm{~mL} / \mathrm{min}$ constant flux. The injector was programmed to inject a volume of $20 \mu \mathrm{L}$. The solvent systems used were: $\mathrm{CH}_{3} \mathrm{CN}: \mathrm{H}_{2} \mathrm{O}$ 50:50 and 60:40, and isocratic HPLC mode was used.

Ultraviolet spectroscopy was performed using a Femto spectrophotometer. The wavelength used in the solubility

B

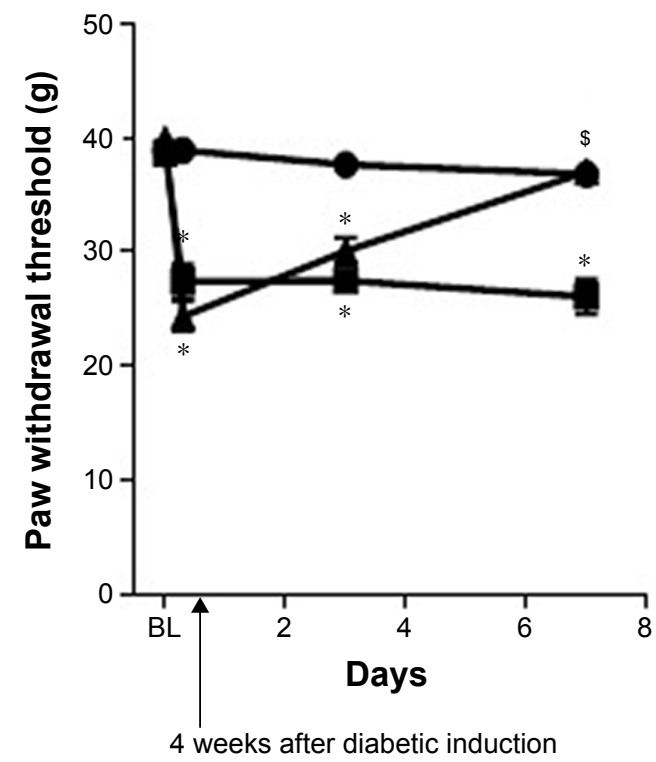

\section{- Non-diabetic STZ + DMSO}

Figure 7 Effect of administration of compound 7 (LASSBio- I773) on diabetic neuropathy.

Notes: Temporal changes in paw withdrawal latency $(\mathbf{A})$ and paw withdrawal threshold $(\mathbf{B})$ during 7 days of treatment. Values are expressed as mean \pm standard error of the mean; $n=5$ per group. Two-way analysis of variance test was used for comparison among groups. $* P<0.05$ compared before treatment (BL) and ${ }^{\$} P<0.05$ compared to vehicle (DMSO).

Abbreviations: DMSO, dimethyl sulfoxide; STZ, streptozotocin; s, seconds. 
assay was determined by the $\lambda_{\max }$ characteristic of each compound. Spectra were analyzed with Femtoscan software.

\section{Procedure to prepare 3,4-dimethoxy- benzenesulfonohydrazide (12)}

A solution of the appropriate sulfonyl chloride (11) (4.24 mmol) at $0^{\circ} \mathrm{C}$ for 5 minutes was slowly added to a stirred solution of hydrazine hydrate $(16.95 \mathrm{mmol})$ in $\mathrm{CHCl}_{3}$ $(20 \mathrm{~mL})$. The reaction mixture was stirred at room temperature for 4 hours until the end of the reaction. Subsequently, $30 \mathrm{~mL}$ water saturated with $\mathrm{NaCl}$ was added. The layers were separated, and the aqueous phase was extracted with $\mathrm{CH}_{2} \mathrm{Cl}_{2}$ (three times with $30 \mathrm{~mL}$ each time). The combined organic layers were dried over $\mathrm{Na}_{2} \mathrm{SO}_{4}$ and filtered, and the solvent was removed under reduced pressure. No further purification of the product was required. Adapted from reference 13.

Derivative (12), 3,4-dimethoxybenzenesulfonohydrazide was obtained as a white solid with $91 \%$ yield.

${ }^{1} \mathrm{H}$ NMR (200 MHz, DMSO-d $\left.{ }_{6}\right) \delta$ (ppm): 8.20 (s, 1H), 7.39 (dd, J =8 Hz, J =2 Hz, 1H), 7.29 (s, 1H, J =2 Hz), 7.11 (d, J =8 Hz, 1H), 4.2 (s, 2H), 3.77 (s, 3H), 3.74 (s, 3H).

\section{Procedure to prepare 3,4-dimethoxy-N- methylbenzenesulfonohydrazide (I3)}

In a reaction flask, 3,4-dimethoxybenzenesulfonohydrazide (12, $4.31 \mathrm{mmol})$ and phthalic anhydride $(6.45 \mathrm{mmol})$ were added. The mixture was heated to $130^{\circ} \mathrm{C}$ without solvent for 2 hours to complete the reaction. The crude solid formed was washed with water with $10 \%$ sodium carbonate. Then, the crude solid (3.87 mmol) was added, without a previous purification step, to a stirred acetone suspension with sodium carbonate (4.31 $\mathrm{mmol})$ and $\mathrm{ICH}_{3}(8.62 \mathrm{mmol})$. The mixture was heated to $50^{\circ} \mathrm{C}$ until the end of the reaction after 18 hours. Next, $50 \mathrm{~mL}$ of an aqueous solution of $10 \%$ sodium carbonate was added, the layers were separated, and the aqueous phase was extracted with ethyl acetate (three times with $50 \mathrm{~mL}$ each time). The organic phase was reduced under negative pressure, obtaining a white solid, which was added to a solution of hydrazine hydrate $(17.24 \mathrm{mmol})$ in ethanol $(50 \mathrm{~mL})$ for 5 hours at $80^{\circ} \mathrm{C}$ until completion of the deprotection step. Then the solvent was reduced under negative pressure, and $30 \mathrm{~mL}$ of water with $10 \%$ sodium carbonate and $\mathrm{CH}_{2} \mathrm{Cl}_{2}$ were added. The layers were separated, and the aqueous phase was extracted (three times with $50 \mathrm{~mL}$ of $\mathrm{CH}_{2} \mathrm{Cl}_{2}$ each time), and an orange solid with $39 \%$ yield was obtained after the concentration step. ${ }^{13}$

${ }^{1} \mathrm{H}$ NMR $\left(200 \mathrm{MHz}, \mathrm{CDCl}_{3}\right) \delta(\mathrm{ppm}): 7.12(\mathrm{dd}, 1 \mathrm{H}$, $\mathrm{J}=8 \mathrm{~Hz}, \mathrm{~J}=2 \mathrm{~Hz}), 7.10$ (s, J =2 Hz), 6.85 (d, J =8 Hz, 1H), 4.40 (s, 2H), 3.72 (s, 3H), 3.70 (s, 3H), 3.42 (s, 3H).

\section{General procedure for the synthesis of sulfonylhydrazones 4- I 0}

A mixture of the required 3,4-dimethoxybenzenesulfonohydrazide (12) or 3,4-dimethoxy-N-methylbenzenesulfonohydrazide (13) $(0.5 \mathrm{mmol})$ and the appropriate aldehyde $(0.5 \mathrm{mmol})$ was dissolved in ethyl alcohol (20 $\mathrm{mL}$ ) and was vigorously stirred for 30-120 minutes at room temperature. Once the reaction was completed, the product was precipitated by the dropwise addition of cold water. Following filtration, the precipitate was washed with $\mathrm{H}_{2} \mathrm{O}(10 \mathrm{~mL})$ and $\mathrm{n}$-hexane $(10 \mathrm{~mL})$ and dried in vacuum. ${ }^{13}$

\section{(E)-3-((2-(3,4-dimethoxyphenylsulfonyl) hydrazono)methyl)benzoic acid (4, LASSBio- I775)}

Compound 4 (LASSBio-1775) was obtained as a white solid through condensation of 3,4-dimethoxybenzenesulfonohydrazide (12) with methyl 3-formylbenzoic acid with 99\% yield.

${ }^{1} \mathrm{H}$ NMR (200 MHz, DMSO-d $)_{6} \delta$ (ppm): 11.44 (s, 1H), 8.13 (s, 1H), 7.95 (s, 1H), 7.91 (d, J =7.7 Hz, 1H), 7.76 (d, J =7.7 Hz, 1H), 7.49 (t, J =8.2 Hz, 1H), 7.43 (dd, $\mathrm{J}=8.2 \mathrm{~Hz}, 1 \mathrm{H}), 7.33$ (d, J =1.8 Hz, 1H), $7.11(\mathrm{~d}, \mathrm{~J}=8.2 \mathrm{~Hz}$, $1 \mathrm{H}), 3.78$ (s, 6H).

${ }^{13} \mathrm{C}$ NMR (50 MHz, DMSO-d $)$ ) $\delta$ (ppm): 166.94, 152.52, 148.62 , 146.11, 134.24, 131.43, 131.29, 130.67, 130.46, 129.34, 127.04, 121.00, 111,35, 109.95, 55.92, 55.80.

HPLC 60/40 acetonitrile/water: $98.09 \%$ purity (Retention Time $[\mathrm{RT}]=3.15,254 \mathrm{~nm}$ ).

\section{(E)-methyl 3-((2-(3,4-}

\section{dimethoxyphenylsulfonyl)-2-} methylhydrazono)methyl)benzoate (5, LASSBio- 1853)

Compound 5 (LASSBio-1853) was obtained as a white solid through condensation of 3,4-dimethoxy-N-methylbenzenesulfonohydrazide (13) with methyl 3-formylbenzoate $62 \%$ yield.

${ }^{1} \mathrm{H}$ NMR (200 MHz, DMSO-d $) \delta(\mathrm{ppm}): 8.26(\mathrm{~s}, 1 \mathrm{H})$, 8.00-7.87 (m, 3H), 7.58 (t, J =8 Hz, 1H), 7.44 (dd, J =8, 2.0 $\mathrm{Hz}, 1 \mathrm{H}), 7.31$ (d, J =2.0 Hz, 1H), 7.14 (d, J =8 Hz, 1H), 3.88 (s, 3H), 3.79 (s, 3H), 3.19 (s, 3H).

${ }^{13} \mathrm{C}$ NMR (50 MHz, DMSO-d $\left.{ }_{6}\right) \delta$ (ppm): 165.77, 152.85, $148.51,142.82$, 134.85, 131.39, 130.16, 129.35, 127.09, $126.96,121.49,111.25,110.21,55.82,55.61,52.27,33.54$.

HPLC 60/40 acetonitrile/water: $97.73 \%$ purity $(\mathrm{RT}=8.12$, $254 \mathrm{~nm})$. 
(E)-methyl 4-((2-(3,4-

dimethoxyphenylsulfonyl)-2-

methylhydrazono)methyl)benzoate

(6, LASSBio- I774)

Compound 6 (LASSBio-1774) was obtained as a white solid through condensation of 3,4-dimethoxy-N-methylbenzenesulfonohydrazide (13) with methyl 4-formylbenzoate with $75 \%$ yield.

${ }^{1} \mathrm{H}$ NMR (200 MHz, DMSO-d $\left.{ }_{6}\right) \delta(\mathrm{ppm}): 7.99$ (d, J =8.2 Hz, 2H), 7.84 (s, 1H), 7.78 (d, J =8.2 Hz, 2H), 7.43 (dd, J =8.4, $2 \mathrm{~Hz}, 1 \mathrm{H}), 7.27$ (s, J =2 Hz, 1H), 7.12 (d, J =8.4 Hz, 1H), 3.84 (s, 3H), 3.79 (s, 3H), 3.76 (s, 3H), $3.18(\mathrm{~s}, 3 \mathrm{H})$.

${ }^{13} \mathrm{C}$ NMR (50 MHz, DMSO-d $) ~ \delta$ (ppm): 165.68, 152.41, $148.50,145.37,137.98,130.37,130.29,129.53,126.78$, $120.96,111.22,109.73,55.75,55.72,52.15$.

HPLC 60/40 acetonitrile/water: $96.68 \%$ purity $(\mathrm{RT}=7.89$, $254 \mathrm{~nm})$.

(E)-methyl 4-((2-(3,4dimethoxyphenylsulfonyl)hydrazono) methyl)benzoate (7, LASSBio- 1773)

Compound 7 (LASSBio-1773) was obtained as a white solid through condensation of 3,4-dimethoxybenzenesulfonohydrazide (12) with methyl 4-formylbenzoate with 99\% yield.

${ }^{1} \mathrm{H}$ NMR (200 MHz, DMSO-d 6 ) $\delta$ (ppm): $11.61(\mathrm{~s}, 1 \mathrm{H})$, $7.96(\mathrm{~m}, 3 \mathrm{H}), 7.71$ (d, J =8 Hz, 2H), 7.48 (dd, J =8.5, 2.1 Hz, $1 \mathrm{H}), 7.35$ (d, J =2.1 Hz, 1H), 7.14 (d, J =8.5 Hz, 1H), 3.84 (s, 3H), $3.81(\mathrm{~s}, 6 \mathrm{H})$.

${ }^{13} \mathrm{C}$ NMR (50 MHz, DMSO-d $)$ ) $\delta$ (ppm): 165.68, 152.41, $148.50,145.37,137.98,130.37,130.29,129.53,126.78$, 120.96, 111.22, 109.73, 55.75, 55.72, 52.15.

HPLC 60/40 acetonitrile/water: $95.47 \%$ purity $(\mathrm{RT}=7.07$, $254 \mathrm{~nm})$.

\section{(E)-N'-(4-cyanobenzylidene)-3,4- dimethoxybenzenesulfonohydrazide (8, LASSBio-I77I)}

Compound 8 (LASSBio-1771) was obtained as a yellow solid through condensation of 3,4-dimethoxybenzenesulfonohydrazide (12) with 4-formylbenzonitrile with $77 \%$ yield.

${ }^{1} \mathrm{H}$ NMR (200 MHz, DMSO-d $)$ ) $\delta$ (ppm): 11.38 (s, 1H), $7.95(\mathrm{~s}, 1 \mathrm{H}), 7.84$ (d, J =8.3 Hz, 2H), 7.77 (d, J =8.3 Hz, 2H), 7.46 (dd, J =8.5, 2.0 Hz, 1H), 7.32 (d, J =2.0 Hz, 1H), 7.13 $(\mathrm{d}, \mathrm{J}=8.5 \mathrm{~Hz}, 1 \mathrm{H}), 3.80$ (s, 3H), 3.79 (s, 3H).
${ }^{13} \mathrm{C}$ NMR (50 MHz, DMSO-d $): \delta(p p m) 152.49,148.54$, $144.72,138.04,132.68,130.23,127.22,121.06,118.52$, $111.52,111.89,111.27,109.72,55.80,55.77$.

HPLC 60/40 acetonitrile/water: $99.52 \%$ purity $(\mathrm{RT}=5.00$, $254 \mathrm{~nm})$.

\section{(E)-N'-(4-cyanobenzylidene)-3,4-} dimethoxy-N-methylbenzenesulfonohydrazide (9, LASSBio- I 772)

Compound 9 (LASSBio-1772) was obtained as a yellow solid through condensation of 3,4-dimethoxy-N-methylbenzenesulfonohydrazide (13) with 4-formylbenzonitrile with $91 \%$ yield.

${ }^{1} \mathrm{H}$ NMR $\left(200 \mathrm{MHz}, \mathrm{DMSO}-\mathrm{d}_{6}\right) \delta(\mathrm{ppm}): 7.89$ $(\mathrm{d}, \mathrm{J}=8.0 \mathrm{~Hz}, 2 \mathrm{H}), 7.86(\mathrm{~s}, 1 \mathrm{H}), 7.83$ (d, J =8.0 Hz, 2H), 7.45 (d, J =8.5 Hz, 1H), 7.28 (s, 1H), 7.15 (d, J =8.5 Hz, 1H), $3.81(\mathrm{~s}, 3 \mathrm{H}), 3.78(\mathrm{~s}, 3 \mathrm{H}), 3.21(\mathrm{~s}, 3 \mathrm{H})$.

${ }^{13} \mathrm{C}$ NMR (50 MHz, DMSO-d 6 ) $\delta$ (ppm): 152.96, 148.59, 141.48 , 138.64, 132.76, 127.32, 127.05, 121.65, 118.61, $111.69,111.34,110.12,55.85,55.81,33.46$.

HPLC 60/40 acetonitrile/water: $97.71 \%$ purity $(\mathrm{RT}=7.52$, $254 \mathrm{~nm})$

\section{(E)-4-((2-(3,4-dimethoxyphenylsulfonyl) hydrazono)methyl)benzoic acid LASSBio-I 934 (I0)}

Compound 10 (LASSBio-1934) was obtained as a white solid through condensation of 3,4-dimethoxybenzenesulfonohydrazide (12) with methyl 4-formylbenzoic acid with 99\% yield.

${ }^{1} \mathrm{H}$ NMR (200 MHz, DMSO-d $)_{6} \delta$ (ppm): 11.53 (s, 1H), $7.93(\mathrm{~s}, 1 \mathrm{H}), 7.91$ (d, J =8.4 Hz, 2H), 7.65 (d, J =8.4 Hz, 2H), 7.44 (dd, J =8.6, 2.1 Hz, 1H), 7.32 (d, J =2.1 Hz, 1H), 7.11 (s, J =8.6 Hz, 1H), 3.77 (s, 3H), 3.78 (s, 3H).

${ }^{13} \mathrm{C}$ NMR (50 MHz, DMSO-d 6 ) $\delta$ (ppm): 166.95, 152.56, $148.65,145.76,137.76,131.80,130.43,129.86,126.84$, 121.16, 111.37, 109.86, 56.15, 55.91.

HPLC 60/40 acetonitrile/water: $98.90 \%$ purity $(\mathrm{RT}=3.05$, $254 \mathrm{~nm})$.

\section{Solubility assay}

The solubility assay was performed considering the absorptivity of compounds under ultraviolet spectroscopy as described by Schneider et al. ${ }^{18}$ Assay wavelength was determined through $\lambda_{\max }$ characteristic of each compound. Saturated aqueous solutions were prepared $(0.8-1.0 \mathrm{mg} / \mathrm{mL})$ and kept under stirring for 4 hours at $37^{\circ} \mathrm{C}$. The supernatant was filtered in $0.45 \mathrm{~mm}$ filters and transferred to a quartz 
cuvette $(10 \mathrm{~mm})$ for spectra acquisition. Solubility was determined by linear regression used as Excel graph plots, solutions were prepared by dilutions of the original solution in methanol. Data were collected in triplicate and the mean values were used to create the graph plots. The correlation coefficient $\left(R^{2}\right)$ values were between 0.9982 and 1 .

\section{Rat plasma stability studies}

For conducting these studies, rat plasma was obtained from blood by centrifugation and diluted in phosphate buffer ( $\mathrm{pH} 7.4$ ) to obtain a final plasma concentration of $80 \%$. After that, test compounds were added at a final concentration of $20 \mu \mathrm{M}$ with $250 \mu \mathrm{L}$ of final volume and incubated at $37^{\circ} \mathrm{C}$ for 60 minutes under agitation. At the end of the incubation time, the reaction was stopped by the addition of $450 \mu \mathrm{L}$ of $\mathrm{MeOH}$ and $450 \mu \mathrm{L}$ of $\mathrm{CH}_{3} \mathrm{CN}$. The three independent experiments were performed in duplicate. The samples were centrifuged and filtered for HPLC-UV analysis. ${ }^{20}$

\section{HPLC-UV analysis}

The organic fraction was analyzed with the Shimadzu Prominence HPLC system (Shimadzu, Tokyo, Japan) consisting of a vacuum degasser (DGU-20A5), a binary pump (LC-20AD), an autosampler (SIL-20A), UV/VIS Photodiode Array Detector (SPD-M20A), and fitted with a guard column (CLC G-ODS) and Kromasil 100-5C18 (4.6×250 mm) analytical column running at room temperature. Gradient elution was performed with acetonitrile-water $(50: 50 \mathrm{v} / \mathrm{v}-90: 10 \mathrm{v} / \mathrm{v}-$ $50: 50 \mathrm{v} / \mathrm{v}$ ), at a flow rate set at $1.0 \mathrm{~mL} / \mathrm{min}$. The mobile phase $\mathrm{pH}$ was adjusted to 7.0 with $\mathrm{NH}_{4} \mathrm{OH}$ solution. The detection was carried out at $254 \mathrm{~nm}$ wavelength.

\section{HPLC/MS analysis}

The organic fraction was analyzed with the Shimadzu Prominence HPLC system (Shimadzu) consisting of a vacuum degasser (DGU-20A5), a binary pump (LC-20AD), an autosampler (SIL-20A), UV/VIS Photodiode Array Detector (SPD-M20A), and fitted with a guard column (CLC G-ODS) and a Shimadzu (CLC-ODS, M) column $(250 \times 4.6 \mathrm{~mm}$ internal diameter $)$ running at $20^{\circ} \mathrm{C}$. Gradient elution was performed with acetonitrile-water (50:50 $\mathrm{v} / \mathrm{v}-90: 10 \mathrm{v} / \mathrm{v}-50: 50 \mathrm{v} / \mathrm{v})$, at a flow rate set at $1.0 \mathrm{~mL} /$ min. The mobile phase $\mathrm{pH}$ was adjusted to 7.0 with $\mathrm{NH}_{4} \mathrm{OH}$ solution. The detection was carried out at $254 \mathrm{~nm}$ wavelength. Compounds 7 and 8 and their metabolites (M) were detected with electrospray ionization MS (HPLC-ESI-MS) model Esquire 6000-ESI Ion Trap MSn System Bruker Daltonics (LASSBio ${ }^{\circledR}$-UFRJ) performed with ESI in positive and negative mode. The capillary voltage was $4.0 \mathrm{mV}$. The collision energy was set at $25 \mathrm{eV}$ using helium as collision gas. Nitrogen nebulizer gas flow was $4.0 \mathrm{~L} / \mathrm{min}$, temperature was $250^{\circ} \mathrm{C}$, and pressure was 15 psi. The LC-ESI-MS chromatograms were obtained by scanning over $\mathrm{m} / \mathrm{z} 100-1,000$ range.

\section{pKa analysis}

The pKa assay was performed considering the absorptivity of compounds in ultraviolet spectroscopy, and the buffer solutions ( $\mathrm{pH}$ of 3.0-12) were prepared as described by Martínez and Dardonville. ${ }^{19}$ DMSO stock solutions of the compounds were prepared at $10 \mathrm{mM}$ for the more soluble compounds, and $5 \mathrm{mM}$ for the less soluble compounds. Standard solutions were prepared by adding $4 \mu \mathrm{L}$ of the stock solution in $196 \mu \mathrm{L}$ of buffer solution in each well of the microplate, getting a final concentration of $0.2 \mathrm{mM}$ and $0.1 \mathrm{mM}$ analyte, respectively. UV spectra were recorded on a SpectraMAx apparatus between 200 and $500 \mathrm{~nm}$ at 2 $\mathrm{nm}$ resolution. The data were processed using Excel. pKa values were established by nonlinear regression (GraphPad Prism 5 program).

\section{Chemical stability assays}

Chemical stability studies were conducted at two different $\mathrm{pH}$ values (2 and 7.4). ${ }^{20}$ The stock solutions of compounds were prepared at $5 \mathrm{mM}$ to $10 \mathrm{mM}$ concentrations and solubilized in DMSO. Standard solutions were prepared by adding $2 \mu \mathrm{L}$ of the stock solution in $249 \mu \mathrm{L}$ acid buffer (0.2 M potassium chloride and $\mathrm{HCl} 0.2 \mathrm{M} ; \mathrm{pH}=2)$ or basic (dibasic, $\mathrm{pH}=7.4$ ) in an Eppendorf microtube. The mixture was placed in a water bath at $37^{\circ} \mathrm{C}$ under vigorous stirring for $0,30,60$, and 120 minutes. Once the reaction time was over, $249 \mu \mathrm{L}$ of basic buffer (phosphate buffer, $\mathrm{pH}=8.4$ ) was added to neutralize the $\mathrm{pH}$ of the medium in experiments using acidic buffer. Extraction of the compound was performed by adding $1.0 \mathrm{~mL}$ of acetonitrile. The organic phase was separated, filtered, and analyzed by high-performance liquid chromatography photodiode array detection method (acetonitrile/water mobile phase and $50 \%$ to $60 \%$ ).

\section{Acknowledgments}

The authors would like to thank CNPq (BR), FAPERJ (BR), and INCT-INOFAR (BR, 573.564/2008-6 and E-26/170.020/2008) for fellowship and financial support. The authors would also like to thank Matheus da Silva Delgobbo and Dr Carlos Alberto Manssour Fraga. 


\section{Author contributions}

All authors contributed toward data analysis, drafting, and revising the manuscript and agree to be accountable for the work.

\section{Disclosure}

The authors report no conflicts of interest in this work.

\section{References}

1. Veves A, Backonja M, Malik RA. Painful diabetic neuropathy: epidemiology, natural history, early diagnosis, and treatment options. Pain Med. 2008;9(6):660-674.

2. Vinik AI, Nevoret ML, Casellini C, Parson H. Diabetic neuropathy. Endocrinol Metab Clin North Am. 2013;42(4):747-787.

3. Doth AH, Hansson PT, Jensen MP, Taylor RS. The burden of neuropathic pain: a systematic review and meta-analysis of health utilities. Pain. 2010; 149(2):338-344.

4. Brod M, Blum SI, Bushnell DM, Ramasamy A. Development and validation of the Diabetic Peripheral Neuropathic Pain Impact (DPNPI) measure, a patient-reported outcome measure. Qual Life Res. 2015;24(12):3001-3014.

5. Brod M, Pohlman B, Blum SI, Ramasamy A, Carson R. Burden of Illness of Diabetic Peripheral Neuropathic Pain: A Qualitative Study. Patient. 2015;8(4):339-348.

6. Tesfaye S, Boulton AJ, Dyck PJ, et al. Diabetic neuropathies: update on definitions, diagnostic criteria, estimation of severity, and treatments. Diabetes Care. 2010;33(10):2285-2293.

7. Peltier A, Goutman, SA, Callaghan BC. Painful diabetic neuropathy. BMJ. 2014;348:g1799.

8. Snedecor SJ, Sudharshan L, Cappelleri JC, Sadosky A, Mehta S, Botteman M. Systematic review and meta-analysis of pharmacological therapies for painful diabetic peripheral neuropathy. Pain Pract. 2014; 14(2):167-184.

9. Freeman R. New and developing drugs for the treatment of neuropathic pain in diabetes. Curr Diab Rep. 2013;13(4):500-508.

10. Freitag CM, Miller RJ. Peroxisome proliferator-activated receptor agonists modulate neuropathic pain: a link to chemokines? Front Cell Neurosci. 2014;8:238.

11. Ambrosino P, Soldovieri MG, Maria M, Russo C, Taglialatela M. Functional and biochemical interaction between PPAR $\alpha$ receptors and TRPV1 channels: Potential role in PPAR $\alpha$ agonists-mediated analgesia. Pharmacol Res. 2014;87:113-122.

12. Menéndez-Gutiérrez MP, Roszer T, Ricote M. Biology and therapeutic applications of peroxisome proliferator-activated receptors. Curr Top Med Chem. 2012;12(6):548-584.

13. Zapata-Sudo G, Lima LM, Pereira SL, et al. Docking, synthesis and anti-diabetic activity of novel sulfonylhydrazone derivatives designed as PPAR-gamma agonists. Curr Top Med Chem. 2012;12(19): 2037-2048.
14. Lima LM, Trachez MM, de Araujo JS, et al. Novel Partial Agonist of PPAR-Gamma for Treatment of Diabetic Neuropathy in Rats. J Diabetes Metab. 2014;5:392.

15. Palla G, Predieri G, Domiano P, Vignali C, Turner W. Conformational behaviour and $\mathrm{E} / \mathrm{Z}$ isomerization of $\mathrm{N}$-acyl and $\mathrm{N}$-aroylhydrazones. Tetrahedron. 1986;42:3649-3654

16. Rodrigues DA, Ferreira-Silva GÀ, Ferreira AC, et al. Design, Synthesis and Pharmacological Evaluation of Novel N-Acylhydrazone Derivatives as Potent Histone Deacetylase 6/8 Dual Inhibitors. J Med Chem. 2016;59(2):655-670.

17. da Silva TF, Bispo Júnior W, Alexandre-Moreira MS, et al. Novel orally active analgesic and anti-inflammatory cyclohexyl-N-acylhydrazone derivatives. Molecules. 2015;20(2):3067-3088.

18. Schneider P, Hosseiny SS, Szczotka M, Jordan V, Shlitter K. Rapid solubility determination of the triterpenes oleanoic acid and ursolic acid by UV spectroscopy in different solvents. Phytochem Lett. 2009;2:85-87.

19. Martínez CH, Dardonville C. Rapid Determination of Ionization Constants (pK a) by UV Spectroscopy Using 96-Well Microtiter Plates. ACS Med Chem Lett. 2013;4(1):142-145.

20. Alves MA, de Queiroz AC, Alexandre-Moreira MS, et al. Design, synthesis and in vitro trypanocidal and leishmanicidal activities of novel semicarbazone derivatives. Eur J Med Chem. 2015;100: 24-33.

21. Kazakevich Y, Lobrutto R, editors. HPLC for Pharmaceutical Scientistis. 1st ed. New York: Wiley; 2007.

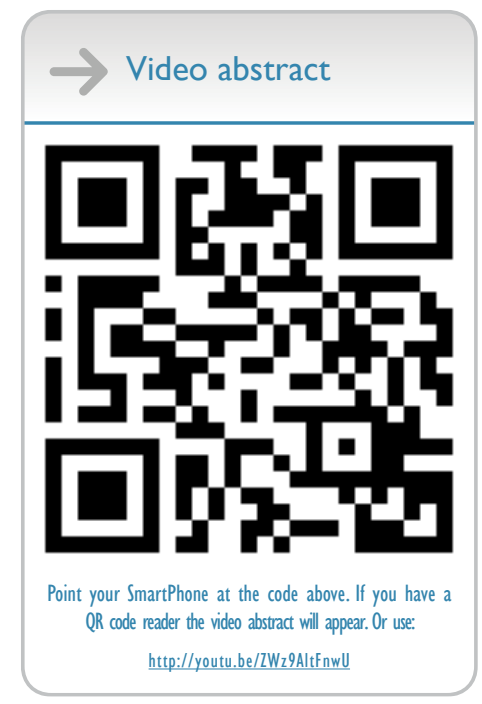

Drug Design, Development and Therapy

\section{Publish your work in this journal}

Drug Design, Development and Therapy is an international, peerreviewed open-access journal that spans the spectrum of drug design and development through to clinical applications. Clinical outcomes, patient safety, and programs for the development and effective, safe, and sustained use of medicines are the features of the journal, which

\section{Dovepress}

has also been accepted for indexing on PubMed Central. The manuscript management system is completely online and includes a very quick and fair peer-review system, which is all easy to use. Visit http://www.dovepress.com/testimonials.php to read real quotes from published authors. 